\title{
Association of plasma endotoxin, inflammatory cytokines and risk of colorectal adenomas
}

\author{
Melissa Kang*, Patrick Edmundson, Felix Araujo-Perez, Amber N McCoy, Joseph Galanko and Temitope O Keku
}

\begin{abstract}
Background: Recent studies suggest that bacterial endotoxins may be associated with various chronic diseases, including colorectal adenomas and cancer. Given the evidence linking inflammation and colorectal cancer, we sought to determine if plasma endotoxin concentrations are associated with indicators of systemic or local inflammation and colorectal adenomas.

Methods: This cross-sectional study consisted of participants who underwent screening colonoscopies and included adenoma cases $(n=138)$ and non-adenoma controls $(n=324)$. Plasma concentrations of endotoxin were measured with Limulus Amebocyte Lysate (LAL) assay. We quantified concentrations of inflammatory cytokines, interleukin-4 (IL-4), IL-6, IL-8, IL-10, IL-12, tumor necrosis factor-alpha (TNF-a), and interferon- $\gamma$ (IFN- $\gamma$ ) in plasma by ELISA and mRNA expression levels in rectal mucosal biopsies by quantitative RT-PCR. Interleukin-17 was evaluated only in the rectal mucosa.
\end{abstract}

Results: Compared to subjects with low plasma endotoxin concentrations, those with higher concentrations were more likely to have adenomas (OR 1.4, 95\% Cl 1.0-2.1). Among subjects with adenomas, those with villous histology were more likely to have higher endotoxin concentrations (5.4 vs. $4.1 \mathrm{EU} / \mathrm{mL}, \mathrm{p}=0.05)$ and lower plasma IFN- $\gamma(0$ vs. $1.64 \mathrm{pg} / \mathrm{mL}, \mathrm{p}=0.02$ ) compared to those with only tubular adenomas. Cases showed a trend of having higher plasma TNF-a levels than controls ( $p=0.06$ ), but none of the other plasma or rectal mucosal cytokine levels differed between cases and controls. Elevated mucosal IL-12 levels were associated with having multiple adenomas $(\mathrm{p}=0.04)$. Higher concentrations of plasma endotoxin predicted increased plasma IL-12 levels (OR 1.5, 95\% Cl 1.0-2.2) and rectal mucosal IL-12 (OR 1.9, 95\% Cl 1.0-3.7) and IL-17 gene expression (OR 2.2, 95\% Cl 1.0-4.6).

Conclusions: These findings suggest that interactions between elevated plasma endotoxin concentrations and inflammatory cytokines may be relevant to the development of colorectal adenomas.

Keywords: Endotoxin, Inflammatory cytokines, Colonic neoplasm, Adenoma, Limulus amebocyte lysate

\section{Background}

Colorectal cancer $(\mathrm{CRC})$ is one of the leading causes of cancer death in the world and the United States [1] with the majority of cases having no previous family history. Sporadic CRC has been linked to several risk factors including accumulation of genetic mutations, inflammatory states such as inflammatory bowel disease, and environmental factors such as smoking and obesity. More recently, CRC has been linked to changes in the gut microbiota [2-5]. While bacterial dysbiosis has been

\footnotetext{
*Correspondence: melissa_kang@med.unc.edu Center for Gastrointestinal Biology and Disease, University of North Carolina,
103 Mason Farm Road, 7340 Medical Biomolecular Research Building, CB \# 103 Mason Farm Road, 7340 Medical Biomolecular Research Building, CB \# 7032, Chapel Hill, NC 27599-7032, USA
}

associated with CRC, the mechanism by which it promotes colon carcinogenesis has not been elucidated. As adenomas are known CRC precursors, studies to determine risk factors for adenomas could be crucial to prevention and treatment of CRC. Consequently, identifying the role of gut bacteria, microbial products, and their effect on inflammation can further aid in our understanding of CRC pathogenesis.

The human intestine is a complex and unique environment inhabited by $10^{13}$ bacteria that interact with the intestinal mucosa to affect gut immunity and homeostasis [6-9]. An imbalance of the bacterial population in favor of pro-oncogenic bacteria could lead to abnormal
C Biomed Central

(c) 2013 Kang et al.; licensee BioMed Central Ltd. This is an Open Access article distributed under the terms of the Creative Commons Attribution License (http://creativecommons.org/licenses/by/2.0), which permits unrestricted use, distribution, and reproduction in any medium, provided the original work is properly cited. 
proliferation of the colonic epithelium and adenoma formation $[10,11]$. Although previous studies have reported an association between gram-positive bacteria, Streptococcus gallolyticus (formerly $S$. bovis) and colorectal neoplasia [12], we have demonstrated that an increased abundance of Proteobacteria, a decreased abundance of Bacteroides, and a disproportionate colonization of the gut with predominant Escherichia coli were associated with adenomatous states [13,14]. More recently, Kostic et al. observed that Fusobacterium were enriched in $\mathrm{CRC}$, also supporting a role of gram-negative bacteria in colorectal carcinogenesis [2]. One of the proposed mechanisms by which $S$. gallolyticus promotes development of colorectal tumors is through the production of inflammatory cytokines by the release of their cell wall antigens [12]. Thus, bacterial dysbiosis that favors higher abundance of gram-negative bacteria could contribute to the formation of adenomas via increased endotoxin release and inflammation.

Endotoxin, or lipopolysaccharide (LPS), is a component of the cell wall of gram negative bacteria and is released into the host environment by the destruction of the cell wall. Studies have shown that certain bacterial types are correlated with elevated concentrations of plasma endotoxin $[15,16]$, which can have detrimental effects. Under experimental conditions, endotoxin binds to LPS-binding protein to form a complex with CD14, which leads to activation of toll-like receptor 4 (TLR-4), initiation of innate inflammatory response, activation of macrophages and monocytes, and production of pro-inflammatory cytokines such as tumor necrosis factor- $\alpha$ (TNF- $\alpha$ ), interleukin (IL)-6, and IL-23 [15-20]. An overabundance of LPS-rich bacteria in the gut may provide an environment that is conducive for chronic inflammation and increased production of pro-inflammatory cytokines and reactive oxygen species. These cytokines can activate the NF- $\kappa \beta$ pathway, which has been implicated in cell proliferation and DNA damage leading to carcinogenesis [17-20].

The aim of our study was to determine the relationship between plasma endotoxin, systemic and local inflammation, and colorectal adenomas. We assessed the association between plasma endotoxin concentrations, plasma cytokines IL-4, IL-6, IL-8, IL-10, TNF- $\alpha$, and interferon- $\gamma$ (IFN- $\gamma$ ) levels, and local cytokine mRNA expression levels of IL-4, IL-6, IL-8, IL-10, IL-17, TNF- $\alpha$, and IFN- $\gamma$ in relation to adenomas.

\section{Methods}

Study population. The study population and data collection were as previously described $[13,14]$. The subjects in this cross-sectional study were drawn from the Diet and Healthy Study V (DHSV), where participants underwent screening colonoscopies at the University of
North Carolina at Chapel Hill Hospitals. Eligibility requirements were as follows: age $\geq 30$ years; proficiency in English to provide informed written consent and participate in a phone interview; a satisfactory preparation for colonoscopy and complete examination to the cecum; outpatient; no history of familial polyposis, colitis, previous colonic resection, previous colon cancer or polyps; and had not taken antibiotics within 12 weeks prior to the colonoscopy. Information about diet and lifestyle was collected by telephone interview for each subject within 12 weeks of the colonoscopy. Anthropometric measures were obtained on the day of the colonoscopy. Rectal mucosal biopsies taken at $10-12 \mathrm{~cm}$ from the anal verge were obtained during colonoscopy. All participating subjects provided written informed consents and consented to blood samples. Subjects who had adenomatous polyps at colonoscopy were classified as cases $(n=138)$ and subjects without adenomas as controls $(n=324)$. The study was approved by the Institutional Review Board at the University of North Carolina, School of Medicine (Protocol \#05-3138).

Plasma endotoxin assay. Blood samples were collected in EDTA-containing tubes, and plasma was separated by centrifugation. Plasma samples were frozen in small aliquots at $-80^{\circ} \mathrm{C}$ to prevent repeated freezing and thawing until analysis. Plasma endotoxin concentrations were measured using a commercially available quantitative chromogenic endpoint Limulus Amebocyte Lysate (LAL) QCL-1000 kit (Lonza, Walkersville, MD). Briefly, $300 \mu$ of plasma was diluted 1:3 with $10 \mathrm{mM} \mathrm{MgCl}_{2}$ (Lonza), then heat inactivated at $70^{\circ} \mathrm{C}$ for $30 \mathrm{~min}$, followed by further dilutions to $1: 30-1: 40$ and $50 \mu \mathrm{l}$ of the diluted sample was added to a 96-well pyrogen-free culture plate. Remaining procedures were performed according to the manufacturer's instructions. Endotoxin concentrations $(\mathrm{EU} / \mathrm{ml})$ in the samples were determined from a standard curve using pure endotoxin standards. All assays were run in duplicate. The detection range of this kit was $0.1 \mathrm{EU} / \mathrm{ml}$ to $1.0 \mathrm{EU} / \mathrm{ml}$. For samples that were below the lowest standard value, endotoxin concentration was calculated as the blank (negative control) concentration value of 0.055 times the dilution factor. Two samples required much larger dilutions at a ratio of 1:99 and could not be accurately compared to the endotoxin standard curve. These two samples were removed as outliers. The intra-assay and inter-assay coefficients were $4.3 \%$ and $17.2 \%$, respectively.

Quality control for plasma endotoxin assay. Blood samples were collected in EDTA-containing tubes to prevent coagulation. Because LAL is composed of the coagulation system of the horseshoe crab, EDTA can inhibit LAL gel formation by chelating divalent cations in the LAL formulation, thus, depleting the lysate of the cations it needs to function properly. Therefore, samples 
were diluted in $10 \mathrm{mM} \mathrm{MgCl} 2$ to overcome the inhibitory nature of EDTA. This method was proven to pass the positive product control test by the manufacturer. Furthermore, plasma contains protein components that could inhibit the assay. To verify the lack of product inhibition, samples were tested for inhibition according to the manufacturer's instructions. Briefly, samples were either spiked with $0.4 \mathrm{EU} / \mathrm{mL}$ of endotoxin or unspiked. Endotoxin concentrations from both samples were determined. If the difference between spiked and unspiked samples equaled $0.4 \mathrm{EU} / \mathrm{mL}+25 \%$, the sample was considered uninhibited. We performed this on groups of samples and determined that plasma containing hemolyzed red blood cells did not pass the test. Thus, only plasma samples with clear yellow color passed the test and were included in our assay. With these measures, the components potentially interfering with the reaction were minimized.

Enzyme-linked immunosorbent assay (ELISA) of plasma cytokines. ELISA was used to quantify inflammatory cytokines in the plasma samples. Any samples with gross hemolysis or lipemia were not assayed. Plasma samples were thawed and centrifuged to remove any precipitates prior to running the assay. The plasma cytokine assay was performed using the Milliplex high sensitivity human cytokine kit for IL-4, IL-6, IL-8, IL-10, TNF- $\alpha$, and IFN- $\gamma$ (HSCYTO-60SK, Millipore, Billerica, MA) following the manufacturer's recommendation. Plasma samples were mixed with fluorescently labeled, color coded microspheres in 96-well plates and incubated overnight at $4^{\circ} \mathrm{C}$. The next day plates were washed, and a biotinylated detection antibody was added, followed by incubation with agitation for $1 \mathrm{~h}$ at room temperature. Next, Streptavidin-Phycoerythrin was added to each well, followed by incubation for $30 \mathrm{~min}$ and another wash step. Finally, the reaction was read immediately on the Bioplex 200 System (Biorad, Hercules CA). Fluorescent intensities for the samples were derived by fitting on a standard curve. Each assay was run in duplicate with positive controls included in each batch. The average of two measurements was used for data analysis. Minimal detection levels were $0.13 \mathrm{pg} / \mathrm{mL}$ for IL-4, $0.10 \mathrm{pg} / \mathrm{mL}$ for IL-6, $0.11 \mathrm{pg} / \mathrm{mL}$ for IL-8, $0.15 \mathrm{pg} / \mathrm{mL}$ for IL-10, $0.05 \mathrm{pg} / \mathrm{mL}$ for TNF- $\alpha$, and $0.29 \mathrm{pg} / \mathrm{mL}$ for IFN- $\gamma$. The intra-assay and inter-assay coefficients of variation were $4.16 \%$ and $9.12 \%$ for IL-4, 3.51\% and $4.48 \%$ for IL-6, $3.26 \%$ and $6.48 \%$ for $\mathrm{IL}-8,3.31 \%$ and $11.84 \%$ for IL-10, $3.49 \%$ and $3.78 \%$ for $\mathrm{TNF}-\alpha$, and $4.88 \%$ and $7.79 \%$ for IFN- $\gamma$ respectively.

RNA extraction, reverse transcription and quantitative real-time PCR (qRT-PCR) of rectal mucosal biopsies. Rectal biopsies were placed in RNA Later (Qiagen, Valencia, CA) immediately after collection. RNA extraction was performed within 1 week of obtaining the tissue biopsies, and isolated RNA was stored at $-80^{\circ} \mathrm{C}$ in small aliquots to prevent repeated freezing and thawing. Extraction of RNA and qRT-PCR were previously described [21,22]. Briefly, RNA was extracted from tissue biopsies using the Qiagen RNeasy Protect Mini Kit following the manufacturer's protocol (Qiagen, Valencia, CA). RNA purity and concentration were evaluated by Agilent Bioanalyzer (Agilent, Santa Clara, CA) as well as absorbance readings using the NanoDrop ND-1000 spectrophotometer immediately after the extraction (Thermo Scientific, Wilmington, DE). Only samples with an RNA integrity number (RIN) above 7 were used for RT-PCR assays (Agilent, Santa Clara, CA). One $\mu \mathrm{g}$ of total RNA was reverse transcribed (RT) using the Cloned AMV First-Strand cDNA Synthesis Kit (Invitrogen, Grand Island, NY). Commercially available RT-qPCR primers (SABiosciences, Valencia, CA) were obtained for the housekeeping gene, hydroxymethylbilane sythase (HMBS), and seven inflammatory cytokines that included: IL-4, IL-6, IL-8, IL-10, IL-17, TNF- $\alpha$, and IFN- $\gamma$. Each reaction contained $2 \mu \mathrm{L}$ of cDNA, $1 \mu \mathrm{M}$ of each primer, and $5 \mu \mathrm{L}$ of Fast-SYBR Green Master Mix (Applied Biosystems, Carlsbad, CA). Cycling conditions were: 1 cycle at $95^{\circ} \mathrm{C}$ for $10 \mathrm{~min}$ followed by 45 cycles of $95^{\circ} \mathrm{C}$ for $15 \mathrm{~s}, 60^{\circ} \mathrm{C}$ for $1 \mathrm{~min}$, and $72^{\circ} \mathrm{C}$ for $30 \mathrm{~s}$. All samples were run in duplicate for both the target and housekeeping genes. The housekeeping gene was used for normalization. Pooled RNA from control subjects was included with each batch of RT-PCR reaction and served as a reference. This pooled RNA also served as a calibration point across different batches of PCR runs. Transcript abundance was calculated by the delta-delta threshold cycle $(\Delta \Delta \mathrm{Ct})$ method [23]. Additional quality control measures included initial validation of qPCR efficiency for all target genes and the housekeeping gene. Standard curves were generated using dilutions series of standards for target or housekeeping genes and the PCR efficiency was calculated using the method of Pfaffl et al. [24]. The amplification efficiency of the target genes and housekeeping standard were comparable.

Statistical analysis. Participant characteristics were compared using student's $t$-test or a chi squared test. Median concentrations of plasma endotoxin and inflammatory markers were compared between controls and cases by the Mann-Whitney $U$ test as this data was highly skewed and not normally distributed. As a result, we used nonparametric approaches (Mann-Whitney U tests) which do not assume normality.

Plasma endotoxin concentrations in controls were used to determine upper and lower 50\% cut points. Upper and lower halves of plasma endotoxin concentrations were compared between cases and controls using unconditional logistic regression and odds ratio. Plasma cytokines, tissue cytokines, BMI, physical activity, smoking status and daily 
fat intake were tested as potential confounders. Each was added to a logistic regression model with case status as the response and upper or lower halves of endotoxin concentrations as the predictor. If the odds ratios (OR) for the concentrations of endotoxin changed by at least $10 \%$ after the inclusion of the new variable in the model, then that variable was considered to be a potential confounder. After all such potential confounders were identified, they were all entered into the model along with the concentrations of endotoxin, and a backwards stepwise procedure was performed with endotoxin being forced into the model. Ultimately, we identified all tissue cytokines and dietary fat as confounders and ran the final logistic regression model with adjustment for these variables.

Associations between endotoxin concentrations and adenoma size, number, grade and location were also assessed by Mann-Whitney $U$ test. The relationship between each plasma or rectal mucosal cytokine and endotoxin concentrations was also evaluated by multivariate logistic regression while adjusting for the levels of other plasma or rectal mucosal cytokines. P-values less than 0.05 were considered statistically significant while Pvalues greater than 0.05 but less than 0.10 were considered a trend toward significance. P-values were adjusted for multiple comparisons via False Discovery Rate [25].

\section{Results}

We evaluated concentrations of plasma endotoxin and local and systemic inflammatory cytokines from 138 cases and 324 controls. The characteristics of cases and controls are shown in Table 1. Subjects were evenly distributed between males and females and were mostly Caucasians. Compared to controls, cases were slightly older and more likely to be overweight and obese. All adenomas were discovered in the colon, and only 5 subjects had adenomas with a villous component. We analyzed the data using only tubular adenomas, but results were largely unchanged from when we analyzed tubular and villous adenomas together. Thus, we present the data for all adenomas.

The median levels of endotoxin concentrations for cases was $4.1(1.8-26.8 \mathrm{EU} / \mathrm{mL})$ and for controls 3.8 (1.8-26.4 EU/mL). Plasma endotoxin concentrations were divided into higher and lower concentrations based on the cut points in controls. Compared to subjects in low plasma endotoxin concentrations, those with higher concentrations were significantly more likely to have adenomas when adjusted for rectal mucosal cytokines and dietary fat $(\mathrm{OR}=1.4, \mathrm{CI} 95 \%$ 1.0-2.1) (Table 2).

We also assessed whether concentrations of plasma endotoxin were associated with adenoma characteristics.
The average number of adenomas was 1.8 per person (range 1-9). The adenoma size distribution was as follows: small adenoma, 1-5 mm, 66\%; medium adenoma, 6-10 mm, 25\%; large adenoma, >10 mm, 9\% (Table 3). Endotoxin concentration was significantly higher in those with villous adenomas than tubular adenomas $(\mathrm{p}<0.05)$ (Table 3$)$. However, there were no associations between adenoma size or number and endotoxin concentrations.

Median plasma or rectal mucosal cytokine levels were not different between cases and controls, with the exception of plasma TNF- $\alpha$ levels which showed a trend toward being higher in those with adenomas than those without adenomas $(\mathrm{p}=0.06)$ (Table 4, Table 5). We compared plasma and rectal mucosal cytokines between cases with one versus multiple adenomas, cases with at least one adenoma of at least $1 \mathrm{~cm}$ in size versus all adenomas less than $1 \mathrm{~cm}$ in size, and cases with at least one adenoma with villous component versus all

Table 1 General characteristics of study population

\begin{tabular}{|c|c|c|c|}
\hline Characteristics & $\begin{array}{c}\text { Case } \\
(n=138)\end{array}$ & $\begin{array}{l}\text { Control } \\
(n=342)\end{array}$ & $\mathrm{p}$ \\
\hline Age (years), mean (se) & $57.0(0.6)$ & $55.2(0.4)$ & 0.01 \\
\hline \multicolumn{4}{|l|}{ Sex, n (\%) } \\
\hline Male & $72(55)$ & $142(47)$ & 0.12 \\
\hline \multicolumn{4}{|l|}{ Race, n (\%) } \\
\hline White & $121(88)$ & $296(89)$ & 0.73 \\
\hline Black & $16(12)$ & $35(11)$ & \\
\hline BMI, n (\%) & & & 0.03 \\
\hline Normal & $43(32)$ & $147(44)$ & \\
\hline Overweight & $61(45)$ & $113(34)$ & \\
\hline Obese & $32(24)$ & $74(22)$ & \\
\hline Waist/Hip ratio (mean (se)) & $0.934(0.007)$ & $0.907(0.004)$ & 0.001 \\
\hline Calories (kcal/day), mean (se) & $1986(65)$ & $1993(47)$ & 0.92 \\
\hline Smoking Status, n (\%) & & & 0.62 \\
\hline Current & $11(8)$ & $26(9)$ & \\
\hline Former & $41(32)$ & $109(36)$ & \\
\hline Never & $78(60)$ & $166(55)$ & \\
\hline Physical activity & $2263(215)$ & 2565 (159) & 0.28 \\
\hline \multicolumn{4}{|l|}{$\begin{array}{l}\text { (MET minutes per day), mean } \\
\text { (se) }\end{array}$} \\
\hline $\begin{array}{l}\text { Fat intake (grams/day), mean } \\
\text { (se) }\end{array}$ & $75.8(2.8)$ & $77.0(1.9)$ & 0.71 \\
\hline $\begin{array}{l}\text { Number of adenomas, mean } \\
\text { (se) }\end{array}$ & $1.8(0.1)$ & & \\
\hline $\begin{array}{l}\text { Size of adenomas (mm), mean } \\
\text { (se) }\end{array}$ & $5.7(0.4)$ & & \\
\hline \multicolumn{4}{|l|}{ New adenoma histology } \\
\hline Tubular, n (\%) & $100(95)$ & & \\
\hline Villous, n (\%) & $5(5)$ & & \\
\hline
\end{tabular}


adenomas having only tubular components, using Mann-Whitney $U$ test. In subjects with multiple adenomas as compared to those with only one adenoma, only median mucosal IL-12 level was significantly higher (1.09 vs. $0.65, \mathrm{p}=0.04)$. In subjects with villous adenomas, only median plasma IFN- $\gamma$ was significantly lower than in those with only tubular adenomas (0 vs. $1.64 \mathrm{pg} / \mathrm{mL}$, $\mathrm{p}=0.02$ ). None of the other comparisons for number of adenomas or adenoma type and plasma or rectal mucosal cytokines were statistically significant (results not shown).

In addition, we examined the relationship between plasma endotoxin concentrations and a panel of plasma or rectal mucosal cytokines using multivariate logistic regression. We found that those in the upper half of endotoxin concentrations were significantly more likely to have higher plasma IL-12 as compared to those in the lower half of endotoxin concentrations $(\mathrm{OR}=1.5$, CI 95\% 1.0-2.2) (Additional file 1: Table S1). Similarly, those in the upper half of endotoxin concentrations were significantly more likely to have higher mucosal IL-12 $(\mathrm{OR}=1.9, \mathrm{CI} 95 \% 1.0-3.7)$ and mucosal IL-17 (OR=2.2, CI 95\% 1.0-4.6) than those in the lower half of the endotoxin concentrations (Additional file 1: Table S1). No statistically significant results were found for the remaining cytokines.

\section{Discussion}

This study evaluated the relationship between endotoxemia and colorectal adenomas and their association with systemic and mucosal cytokines. We found an association between high endotoxin concentrations and adenomas. Compared to those with low endotoxin concentrations, those with higher endotoxin concentrations were more likely to be cases. We also observed a positive association between villous adenomas and high endotoxin concentrations. Only plasma TNF- $\alpha$ levels showed a trend toward being higher in adenoma cases than controls $(\mathrm{p}=0.06)$. None of the other plasma or rectal mucosal cytokine levels was significantly different between cases and controls. In multivariate analysis, higher concentrations of endotoxin predicted increased plasma levels of IL-12 as well as rectal mucosal gene expression levels of IL-12 and mucosal IL-17. Increased mucosal gene expression level of IL-12 was also associated with multiple adenomas.

Table 2 Association between plasma endotoxin concentrations and presence of adenomas

\begin{tabular}{lcc}
\hline Plasma Endotoxin & $\begin{array}{c}\text { Unadjusted OR } \\
\mathbf{( 9 5 \% ~ C l )}\end{array}$ & $\begin{array}{c}\text { Adjusted OR } \\
\mathbf{( 9 5 \% ~ C l ) *}\end{array}$ \\
\hline Lower Half $(0-3.76 \mathrm{EU} / \mathrm{mL})$ & 1.0 (Ref) & $1.0($ Ref $)$ \\
Upper Half $(3.80-26.39 \mathrm{EU} / \mathrm{mL})$ & $1.4(1.0,2.1)$ & $1.4(1.0,2.1)$ \\
\hline
\end{tabular}

$O R$ odds ratio, $\mathrm{Cl}$ confidence interval.

*adjusted for rectal mucosal cytokines and daily dietary fat.
Table 3 Endotoxin concentration analysis by adenoma characteristics

\begin{tabular}{lccc}
\hline & $\mathbf{n}$ & Median (25th, 75th) & $\mathbf{p}$ \\
\hline Adenoma size & & & \\
1-5 mm & 90 & $4.11(2.21,5.21)$ & 0.44 \\
6-10 mm & 34 & $4.06(2.81,5.38)$ & \\
$>10 \mathrm{~mm}$ & 13 & $4.95(3.44,5.61)$ & \\
Adenoma number & & & \\
$\quad$ 1-2 & 109 & $4.13(2.54,5.27)$ & 0.60 \\
3+ & 29 & $4.22(2.08,5.69)$ & \\
Adenoma grade & & & \\
$\quad$ Tubular & 100 & $4.11(2.19,5.30)$ & 0.05 \\
$\quad$ Villous* & 5 & $5.41(4.86,5.61)$ & \\
Adenoma location & & & \\
$\quad$ Proximal & 50 & $4.14(2.84,5.35)$ & 0.90 \\
$\quad$ Distal & 88 & $4.13(2.19,5.36)$ & \\
\hline
\end{tabular}

*Any adenomas containing villous components were classified as villous.

We found that subjects with adenomas were more likely to have higher endotoxin concentrations, especially those with villous adenomas. High dietary fat intake has been shown to increase endotoxemia [26], and in our study, positive relationship between adenoma status and endotoxemia was maintained even after adjusting for rectal mucosal cytokines and dietary fat. Limited studies have evaluated the association between endotoxins and colorectal adenomas. A recent report by Lee et al. demonstrated that endotoxin concentrations were higher in individuals with polyps, especially dysplastic adenomas. Our results are consistent with their findings [27]. To our knowledge, these are the first studies to show that higher endotoxin concentrations are associated with adenoma risk in humans. While Lee et al. did not evaluate any mechanisms that could explain the endotoxin relationship to adenomas, we propose that bacterial dysbiosis in favor of overabundance of gram-negative bacteria in individuals with adenomas could lead to increased endotoxin release, and thereby contribute to elevated production of inflammatory cytokines. This, in turn, could promote leakiness of the intestinal mucosal barrier and translocation of endotoxin into the blood stream. A recent study showed that intraluminal administration of LPS in the colon resulted in altered local cytokine production suggesting that elevated LPS in the colon is able to cause intestinal inflammation [28].

Chronic inflammation is a risk factor for colorectal cancer. We have previously shown that elevated levels of plasma IL- 6 and TNF- $\alpha$ are associated with increased risk of adenomas [21]. In this study, we found a borderline association between plasma TNF- $\alpha$ levels and colorectal adenomas. Evaluation of the relationship between 
Table 4 Comparison of plasma concentration of endotoxin and plasma cytokine levels among cases and controls

\begin{tabular}{|c|c|c|c|c|}
\hline Plasma levels, units & $\begin{array}{c}\text { Case }(n=138) \\
(\text { median }(\min , \max ))\end{array}$ & $\begin{array}{c}\text { Control }(\mathrm{n}=342) \\
(\text { median }(\min , \max ))\end{array}$ & $p$ & $\begin{array}{c}\text { Adjusted } \\
\mathrm{p}^{*} \\
\end{array}$ \\
\hline TNF-a (pg/mL) & $4.8(1.3,276.6)$ & $4.3(0,268.3)$ & 0.008 & 0.06 \\
\hline IL-4 (pg/mL) & $4.3(0,916.5)$ & $2.6(0,5459.2)$ & 0.07 & 0.19 \\
\hline IL-6 (pg/mL) & $4.1(0,1099.1)$ & $4.0(0,911.1)$ & 0.70 & 0.80 \\
\hline IL-8 (pg/mL) & $3.0(0,131.2)$ & $2.7(0,291.1)$ & 0.07 & 0.19 \\
\hline IL-10 (pg/mL) & $8.5(0,1644.7)$ & $7.4(0,1308.8)$ & 0.60 & 0.80 \\
\hline IL-12 (pg/mL) & $0.5(0,716.1)$ & $0.5(0,1106.3)$ & 0.82 & 0.82 \\
\hline IFN- $\gamma(p g / m L)$ & $1.4(0,924.8)$ & $1.5(0,390.0)$ & 0.57 & 0.80 \\
\hline
\end{tabular}

TNF tumor necrosis factor, IL interleukin, IFN Interferon.

* adjusted for multiple comparisons via False Discovery Rate.

endotoxin and plasma or mucosal cytokines revealed that plasma IL-12 levels, and rectal mucosal levels of IL-12 and IL-17 were likely to be elevated with increased endotoxin concentrations. This observation for IL-12 is consistent with published literature demonstrating imbalance in Th1 cytokine network in colorectal carcinogenesis $[29,30]$. IL-17 is a pro-inflammatory cytokine that could promote tumorigenesis and tumor progression $[31,32]$. Our observations support an association between plasma endotoxin concentrations and markers of systemic and mucosal inflammation.

When we analyzed rectal mucosal and plasma cytokines in relation to adenoma characteristics, we found that those with villous adenomas were more likely to have lower plasma IFN- $\gamma$. IFN- $\gamma$ is mainly induced by IL- 12 . Elevated levels of IL-12 have been reported in adenomas while decreased levels have been noted in CRC [29,30]. As villous adenomas are more likely to be dysplastic than tubular adenomas and closer in progression to CRC, it is possible that changes in cellular immunity such as altered levels of immune markers, IL-12 and IFN- $\gamma$, could

Table 5 Comparison of tissue cytokine levels among cases and controls

\begin{tabular}{lcccc}
\hline $\begin{array}{l}\text { Tissue } \\
\text { levels, }\end{array}$ & $\begin{array}{c}\text { Case }(\mathbf{n}=111) \\
\text { (median }(\mathbf{m i n}, \\
\text { max)) }\end{array}$ & $\begin{array}{c}\text { Control }(\mathbf{n}=\mathbf{2 7 8}) \\
\left(\begin{array}{c}\text { median }(\mathbf{m i n}, \\
\text { max }))\end{array}\right.\end{array}$ & $\begin{array}{c}\mathbf{p} \\
\text { Adjusted } \\
\mathbf{p}^{* *}\end{array}$ \\
\hline TNF-a & $0.8(0.03,18.6)$ & $0.8(0,18.2)$ & 0.92 & 0.92 \\
IL-4 & $0.5(0,16.0)$ & $0.4(0,14.4)$ & 0.08 & 0.29 \\
IL-6 & $1.0(0.06,41.2)$ & $1.1(0.1,39.1)$ & 0.77 & 0.88 \\
IL-8 & $0.5(0,24.8)$ & $0.5(0,32.4)$ & 0.44 & 0.59 \\
IL-10 & $0.4(0,115.1)$ & $0.6(0,72.9)$ & 0.05 & 0.29 \\
IL-12 & $0.7(0.04,24.3)$ & $0.8(0.01,16.3)$ & 0.34 & 0.54 \\
IL-17 & $0.7(0,12.4)$ & $0.9(0,15.1)$ & 0.11 & 0.29 \\
IFN- $-\gamma$ & $0.8(0.06,56.6)$ & $0.7(0.02,24.8)$ & 0.34 & 0.54 \\
\hline
\end{tabular}

TNF tumor necrosis factor, IL interleukin, IFN Interferon.

* Relative gene expression to HMBS and normalized to pooled RNA of controls.

** adjusted for multiple comparisons via False Discovery Rate. contribute to cancer development. Our results demonstrate that rectal mucosal inflammatory cytokines are positively associated with plasma endotoxin concentrations, particularly for adenoma cases. These results are consistent with prior literature showing a correlation between endotoxemia and inflammatory cytokines and oxidative stress markers, and suggest a role of microbiota in mediation of inflammation and adenoma formation via endotoxin production [14,33].

Given that the gut is colonized by complex bacterial communities, we acknowledge that elevated endotoxin concentrations alone may be insufficient to promote inflammation and adenomas. It is likely that other bacteria or bacterial products may be involved. For, example, Streptococcus gallolyticus (formerly $S$. bovis), a grampositive bacteria, has been associated with colorectal adenomas and cancer [12]. S. gallolyticus is thought to promote increased production of inflammatory cytokines and development of colorectal tumors via the release of cell wall antigens [34]. However, our previous studies, demonstrating an increased abundance of LPS-rich Proteobacteria, particularly Escherichia coli, in association with adenomatous states $[13,14]$ provide a good rationale for evaluating bacterial endotoxins, inflammation and adenomas.

In this study, we used mucosal biopsies obtained from the rectum while the adenomas were found in the colon. The rectum has been routinely sampled in human studies to assess biomarkers of colorectal adenomas and cancer. This is based on the idea of a "field effect" whereby events occurring in the rectum are reflective of events going on elsewhere in the colon [35-39]. Ponz de Leon et al. examined mucosal proliferation in different tracts of the large bowel in subjects with colorectal polyps or cancer and normal controls [40]. They found no significant differences in cell proliferation between mucosal samples taken at various distances from the colorectal cancer margin suggesting that hyper-proliferation of the entire colonic mucosa was common in patients with 
colorectal cancer. Furthermore, we have previously established that decreased apoptosis is a risk factor for adenomas, and lower rates of apoptosis can be detected from normal rectal mucosa distant from adenomatous tissue [36]. This field effect has also been observed with bacterial composition. Momozawa et al. examined seven sites in the gut and noted that there were no significant quantitative or qualitative differences in bacteria from ileum to rectum, suggesting that the majority of bacteria would be similar throughout the large intestine [41]. These studies support that rectal mucosal biopsies could be a good surrogate for biopsies adjacent to adenomas.

We did not have comprehensive medical histories of the subjects. While endotoxin transfer to the bloodstream could be caused by other factors such as tissue damage, infection and other medical conditions that may induce systemic inflammation, all the subjects in our study were ambulatory and healthy enough to undergo outpatient screening colonoscopies. Although, we did not have detailed past infection histories, one of the inclusion criteria was that subjects had not taken antibiotics within 12 weeks prior to colonoscopy, thus, ruling out recent bacterial infections contributing to inflammation.

A limitation of our study is that we used a commercially available endpoint chromogenic LAL test with detection level as its low as $0.1 \mathrm{EU} / \mathrm{ml}$. We chose this method because of its ability to quantitate plasma endotoxin as well as low overall equipment cost. Even though we controlled for protein inhibition of the LAL endotoxin assay, it is possible that there were still components that could interfere with the reaction and potentially obscure the distinction between cases and controls. However, our results are comparable with other studies that evaluated presence of plasma endotoxin in healthy individuals [42-44]. Lastly, we did not measure endotoxin concentrations in the mucosa, which could be more relevant to adenoma formation. We also recognize that with the cross-sectional nature of our study, we cannot establish a causal relationship between endotoxin, inflammation and colorectal adenomas, and that studies in animal models are needed to assess potential mechanisms. This study has several strengths which include a large sample size, detailed exposure information, and evaluation of both local and systemic markers of inflammation.

\section{Conclusion}

To the best of our knowledge, this is one of the first studies to evaluate the association of plasma endotoxin and inflammation in relation to the risk of colorectal adenomas. We found a positive association between plasma endotoxin concentrations and adenomas as well as several measures of rectal mucosal inflammation. In particular, higher levels of endotoxin predicted increased plasma and mucosal IL-12 and mucosal IL-17. Those with villous adenoma histology were more likely to have higher endotoxin but lower plasma IFN- $\gamma$ as compared to those with tubular histology. Thus, our study suggests that bacterial endotoxins are associated with increased levels of plasma and rectal mucosal cytokines, especially in subjects with adenomas.

\section{Additional file}

Additional file 1: Table S1. Odds ratios $(95 \% \mathrm{Cl})$ for elevated levels of cytokines given elevated endotoxin concentrations.

\section{Abbreviations}

CRC: Colorectal cancer; IFN: Interferon; IL: Interleukin; LPS: Lipopolysaccharide; TNF: Tumor necrosis factor.

\section{Competing interests}

The authors declare that they have no competing interests.

\section{Authors' contributions}

MK: planned the details of the study, collected and interpreted data, and drafted the manuscript. PE: collected data. ANM: collected data. FAP: collected data. JAG: performed statistical analysis. TOK: planned the study, interpreted data, and drafted the manuscript. All authors read and approved the final manuscript.

\section{Acknowledgements}

Carlton Anderson read the absorbance of the samples and standards and accordingly calculated endotoxin concentrations.

\section{Financial support}

DHS V (NCI R01 CA 044684), bacteria grant (NCI R01 CA 136887), GI SPORE (P50 CA 106991), CGIBD (P30 DK 034987).

Received: 20 August 2012 Accepted: 18 February 2013

Published: 26 February 2013

\section{References}

1. Jemal A, Bray F, Center MM, Ferlay J, Ward E, Forman D: Global cancer statistics. CA Cancer J Clin 2011, 61(2):69-90.

2. Kostic AD, Gevers D, Pedamallu CS, Michaud M, Duke F, Earl AM, Ojesina Al, Jung J, Bass AJ, Tabernero J, et al: Genomic analysis identifies association of Fusobacterium with colorectal carcinoma. Genome Res 2012, 22(2):292-298

3. Scanlan PD, Shanahan F, Clune Y, Collins JK, O'Sullivan GC, O'Riordan M, Holmes E, Wang Y, Marchesi JR: Culture-independent analysis of the gut microbiota in colorectal cancer and polyposis. Environ Microbiol 2008, 10(3):789-798.

4. Sobhani I, Tap J, Roudot-Thoraval F, Roperch JP, Letulle S, Langella P, Corthier G, Tran Van Nhieu J, Furet JP: Microbial dysbiosis in colorectal cancer (CRC) patients. PLoS One 2011, 6(1):e16393.

5. Wang T, Cai G, Qiu Y, Fei N, Zhang M, Pang X, Jia W, Cai S, Zhao L: Structural segregation of gut microbiota between colorectal cancer patients and healthy volunteers. ISME J 2012, 6(2):320-329.

6. Arumugam M, Raes J, Pelletier E, Le Paslier D, Yamada T, Mende DR, Fernandes GR, Tap J, Bruls T, Batto JM, et al: Enterotypes of the human gut microbiome. Nature 2011, 473(7346):174-180.

7. Li Y, Kundu P, Seow SW, de Matos CT, Aronsson L, Chin KC, Karre K, Pettersson S, Greicius G: Gut microbiota accelerate tumor growth via cjun and STAT3 phosphorylation in APCMin/+ mice. Carcinogenesis 2012, 33(6):1231-1238.

8. Tlaskalova-Hogenova H, Stepankova R, Hudcovic T, Tuckova L, Cukrowska B, Lodinova-Zadnikova R, Kozakova H, Rossmann P, Bartova J, Sokol D, et al: Commensal bacteria (normal microflora), mucosal immunity and chronic inflammatory and autoimmune diseases. Immunol Lett 2004, 93(2-3):97-108. 
9. Vannucci L, Stepankova R, Kozakova H, Fiserova A, Rossmann P, TlaskalovaHogenova H: Colorectal carcinogenesis in germ-free and conventionally reared rats: different intestinal environments affect the systemic immunity. Int J Oncol 2008, 32(3):609-617.

10. Tjalsma H, Boleij A, Marchesi JR, Dutilh BE: A bacterial driver-passenger model for colorectal cancer: beyond the usual suspects. Nat Rev Microbiol 2012, 10(8):575-582.

11. Sears $C L$, Pardoll DM: Perspective: alpha-bugs, their microbial partners, and the link to colon cancer. J Infect Dis 2011, 203(3):306-311.

12. Abdulamir AS, Hafidh RR, Abu Bakar F: The association of Streptococcus bovis/gallolyticus with colorectal tumors: the nature and the underlying mechanisms of its etiological role. J Exp Clin Cancer Res 2011, 30:11.

13. Sanapareddy N, Legge RM, Jovov B, McCoy A, Burcal L, Araujo-Perez F, Randall TA, Galanko J, Benson A, Sandler RS, et al: Increased rectal microbial richness is associated with the presence of colorectal adenomas in humans. ISME J 2012, 6(10):1858-1868

14. Shen XJ, Rawls JF, Randall T, Burcal L, Mpande CN, Jenkins N, Jovov B, Abdo Z, Sandler RS, Keku TO: Molecular characterization of mucosal adherent bacteria and associations with colorectal adenomas. Gut microbes 2010, 1(3):138-147

15. Cani PD, Bibiloni R, Knauf C, Waget A, Neyrinck AM, Delzenne NM, Burcelin $\mathrm{R}$ : Changes in gut microbiota control metabolic endotoxemia-induced inflammation in high-fat diet-induced obesity and diabetes in mice. Diabetes 2008, 57(6):1470-1481

16. Cani PD, Neyrinck AM, Fava F, Knauf C, Burcelin RG, Tuohy KM, Gibson GR, Delzenne NM: Selective increases of bifidobacteria in gut microflora improve high-fat-diet-induced diabetes in mice through a mechanism associated with endotoxaemia. Diabetologia 2007, 50(11):2374-2383.

17. Atreya R, Neurath MF: Signaling molecules: the pathogenic role of the IL6/STAT-3 trans signaling pathway in intestinal inflammation and in colonic cancer. Curr Drug Targets 2008, 9(5):369-374.

18. Langowski JL, Zhang X, Wu L, Mattson JD, Chen T, Smith K, Basham B, McClanahan T, Kastelein RA, Oft M: IL-23 promotes tumour incidence and growth. Nature 2006, 442(7101):461-465.

19. Greten FR, Eckmann L, Greten TF, Park JM, Li ZW, Egan L, Kagnoff MF, Karin M: IKKbeta links inflammation and tumorigenesis in a mouse model of colitisassociated cancer. Cell 2004, 118(3):285-296.

20. Puppa MJ, White JP, Sato S, Cairns M, Baynes JW, Carson JA: Gut barrier dysfunction in the $\mathrm{Apc}(\mathrm{Min} /+)$ mouse model of colon cancer cachexia. Biochim Biophys Acta 2011, 1812(12):1601-1606.

21. Kim S, Keku TO, Martin C, Galanko J, Woosley JT, Schroeder JC, Satia JA, Halabi S, Sandler RS: Circulating levels of inflammatory cytokines and risk of colorectal adenomas. Cancer Res 2008, 68(1):323-328.

22. Jovov B, Araujo-Perez F, Sigel CS, Stratford JK, McCoy AN, Yeh JJ, Keku T: Differential gene expression between African American and European American colorectal cancer patients. PLoS One 2012, 7(1):e30168.

23. Livak KJ, Schmittgen TD: Analysis of relative gene expression data using real-time quantitative $P C R$ and the $2(-$ delta delta $C(T)$ ) method. Methods (San Diego, Calif) 2001, 25(4):402-408.

24. Pfaffl MW: A new mathematical model for relative quantification in realtime RT-PCR. Nucleic Acids Res 2001, 29(9):e45.

25. Benjamini $Y$, Hochberg $Y$ : Controlling the false discovery rate: a practical and powerful approach to multiple testing. J R Stat Soc, Ser B (Methodological) 1995, 57(1):289-300.

26. Pendyala S, Walker JM, Holt PR: A high-fat diet is associated with endotoxemia that originates from the gut. Gastroenterology 2012, 142(5):1100-1101. e1102.

27. Lee KK, Yum KS: Association of endotoxins and colon polyp: a casecontrol study. J Korean Med Sci 2012, 27(9):1062-1065.

28. Im E, Riegler FM, Pothoulakis C, Rhee SH: Elevated lipopolysaccharide in the colon evokes intestinal inflammation, aggravated in immune modulator-impaired mice. Am J Physiol 2012, 303(4):G490-497.

29. Cui G, Yuan A, Goll R, Olsen T, Husebekk A, Vonen B, Florholmen J: Distinct changes of dendritic cell number and IL-12 mRNA level in adjacent mucosa throughout the colorectal adenoma-carcinoma sequence. Cancer Immunol Immunother 2007, 56(12):1993-2001.

30. Contasta I, Berghella AM, Pellegrini P, Adorno D: Passage from normal mucosa to adenoma and colon cancer: alteration of normal sCD30 mechanisms regulating $\mathrm{TH} 1 / \mathrm{TH} 2$ cell functions. Cancer Biother Radiopharm 2003, 18(4):549-557.
31. Murugaiyan G, Saha B: Protumor vs antitumor functions of IL-17. J Immunol 2009, 183(7):4169-4175.

32. Su X, Ye J, Hsueh EC, Zhang Y, Hoft DF, Peng G: Tumor microenvironments direct the recruitment and expansion of human Th17 cells. J Immunol 2009, 184(3):1630-1641.

33. Keku TO, Sandler RS, Simmons JG, Galanko J, Woosley JT, Proffitt M, Omofoye O, McDoom M, Lund PK: Local IGFBP-3 mRNA expression, apoptosis and risk of colorectal adenomas. BMC Cancer 2008, 8:143.

34. Ellmerich S, Scholler M, Duranton B, Gosse F, Galluser M, Klein JP, Raul F: Promotion of intestinal carcinogenesis by streptococcus bovis. Carcinogenesis 2000, 21(4):753-756.

35. Martin C, Connelly A, Keku TO, Mountcastle SB, Galanko J, Woosley JT, Schliebe B, Lund PK, Sandler RS: Nonsteroidal anti-inflammatory drugs, apoptosis, and colorectal adenomas. Gastroenterology 2002, 123(6):1770-1777.

36. Keku TO, Lund PK, Galanko J, Simmons JG, Woosley JT, Sandler RS: Insulin resistance, apoptosis, and colorectal adenoma risk. Cancer Epidemiol Biomarkers Prev 2005, 14(9):2076-2081.

37. Carroll RE, Benya RV, Turgeon DK, Vareed S, Neuman M, Rodriguez L, Kakarala M, Carpenter PM, McLaren C, Meyskens FL Jr, et al: Phase Ila clinical trial of curcumin for the prevention of colorectal neoplasia. Cancer Prev Res (Phila) 2011, 4(3):354-364.

38. Thompson PA, Wertheim BC, Zell JA, Chen WP, McLaren CE, LaFleur BJ Meyskens FL, Gerner EW: Levels of rectal mucosal polyamines and prostaglandin E2 predict ability of DFMO and sulindac to prevent colorectal adenoma. Gastroenterology 2010, 139(3):797-805. 805 e791.

39. Barnes CJ, Hamby-Mason RL, Hardman WE, Cameron IL, Speeg KV, Lee M: Effect of aspirin on prostaglandin E2 formation and transforming growth factor alpha expression in human rectal mucosa from individuals with a history of adenomatous polyps of the colon. Cancer Epidemiol Biomarkers Prev 1999, 8(4 Pt 1):311-315.

40. Ponz De Leon M, Roncucci L, Di Donato P, Tassi L, Smerieri O, Amorico MG, Malagoli G, De Maria D, Antonioli A, Chahin NJ, et al: Pattern of epithelial cell proliferation in colorectal mucosa of normal subjects and of patients with adenomatous polyps or cancer of the large bowel. Cancer Res 1988, 48(14):4121-4126

41. Momozawa Y, Deffontaine V, Louis E, Medrano JF: Characterization of bacteria in biopsies of colon and stools by high throughput sequencing of the V2 region of bacterial 16S rRNA gene in human. PLoS One 2011, 6(2):e16952.

42. Monte SV, Caruana JA, Ghanim H, Sia CL, Korzeniewski K, Schentag JJ, Dandona P: Reduction in endotoxemia, oxidative and inflammatory stress, and insulin resistance after Roux-en- $Y$ gastric bypass surgery in patients with morbid obesity and type 2 diabetes mellitus. Surgery 2012 151(4):587-593.

43. Assimakopoulos SF, Tsamandas AC, Tsiaoussis Gl, Karatza E, Triantos C, Vagianos CE, Spiliopoulou I, Kaltezioti V, Charonis A, Nikolopoulou VN, et al: Altered intestinal tight junctions' expression in patients with liver cirrhosis: a pathogenetic mechanism of intestinal hyperpermeability. Eur J Clin Invest 2012, 42(4):439-446.

44. Lira FS, Rosa JC, Pimentel GD, Souza HA, Caperuto EC, Carnevali LC Jr, Seelaender M, Damaso AR, Oyama LM, de Mello MT, et al: Endotoxin levels correlate positively with a sedentary lifestyle and negatively with highly trained subjects. Lipids Health Dis 2010, 9:82

doi:10.1186/1471-2407-13-91

Cite this article as: Kang et al:: Association of plasma endotoxin, inflammatory cytokines and risk of colorectal adenomas. BMC Cancer 2013 13:91. 